\title{
Analysis of firefighting skill with a teleoperated robot
}

\author{
Yoshihiro Tamura ${ }^{1,2^{*}} \mathbb{0}$, Hisanori Amano ${ }^{2}$ and Jun Ota ${ }^{3}$
}

\begin{abstract}
Teleoperated robots are expected to perform tasks in extreme environments such as disaster sites. However, only few teleoperated robots are used for this purpose because their usability is poor compared to human skill in such tasks. Further, the use of human-machine interfaces used by teleoperated robots is in itself a human skill. In this study, we compare the skills of firefighters (experts) when using teleoperated robots and that of firefighters (novice) and analyze the results. Firefighters gain technical skills required for fighting fires from practical experiences; in comparison, novice firefighters have trouble acquiring these skills. We conducted a comparative experiment of the reconnaissance skills of firefighters in which ten firefighters (five novices and five experts) reconnoiter two simulated fire sites (one in a residential area and the other in a commercial facility area) with a teleoperated robot. The experimental results indicated that experts were more multifaceted in their evaluation of reconnaissance areas as compared to novices.
\end{abstract}

Keywords: Firefighting, Human skill, Teleoperated robot

\section{Introduction}

In recent years, large-scale disasters have occurred frequently globally. Various teleoperated robots have been developed to quickly overcome problems, such as conducting search and rescue for humans and reducing or recovering damage to structures, and improve operational efficiency in disaster areas and dangerous work sites; however, these robots are rarely used. Few of these robots exhibit superior usability in terms of movement and camera operations. In emergencies, it is important to provide the operators of teleoperated robots with a human-machine interface (HMI) that filters input information effectively [1-5]. However, there are few reports of teleoperated robots that reflect this knowledge.

Despite their infrequent current use and poor HMI, the application of teleoperated robots is anticipated for use at the sites of fires because fires are one of the most common disasters that put firefighters at risk. Several

\footnotetext{
*Correspondence: tamura-y@fri.go.jp

${ }^{1}$ Department of Precision Engineering, Graduate School of Engineering,

The University of Tokyo, Tokyo 113-8656, Japan

Full list of author information is available at the end of the article
}

teleoperated robots have been developed for firefighting to reduce the risk to firefighters [6-10].

In addition, because teleoperated robots are work tools, we believe that the effectiveness of the work using a firefighting teleoperated robot depends on the firefighting skills of the operator. Yokokohji et al. [11] summarized various knowledge about the information display method in the rescue robots, but did not mention what kind of information display method is used to assist the skill shortages of operator. To fill the skill gap between novices and experts or to improve the effectiveness of teleoperated robots, several prior studies have evaluated the differences in skill between novices and experts [12-22]. For example, in an investigation of robotic surgery training, Kumar et al. [12] designed evaluation criteria for surgical skills by quantifying objective skill differences between novices and experts. Similarly, Guru et al. [13] evaluated differences in surgical performance with the da Vinci Surgical System for surgeons with different skill levels, ranging from novice to expert. Morioka et al. [14] presented a work information database for cell production assembly created by analyzing the working motions of experts and extracting their skills to improve work efficiency. Roy et al. [15] suggested the usefulness of using 
human-accessible hierarchical semantic labels to teach novices skills acquired by robots from experts.

Other prior studies have examined surgical operations, assembly work in factories, grasping and transportation work in residencies, creative activities with LEGO, communication, and nursing; however, differences in firefighting skill between novices and experts with teleoperated robots are yet to be clarified.

The mission of firefighting is to protect the lives of citizens and properties from fires or disasters. At disaster sites, mistakes by firefighters may result in immediate loss of the lives of many citizens and damages to property. Therefore, firefighting skills are indispensable for maintaining a safe and secure society. However, it is difficult to acquire firefighting skills because fire sites are diverse and most skills of a firefighter are derived from experience. Furthermore, along with the diversification of disasters and the evolution of firefighting equipment, the required firefighting skills have become more complex and advanced. Developing methods to teach firefighting skills is a significant problem in various Japanese fire departments [23]. In one recent countermeasure against this problem, the Tokyo Fire Department proposed methods to support knowledge succession with social networking services [24].

We believe that there are additional opportunities for improving the utility-especially in terms of HMI-of teleoperated robots for firefighting by evaluating the differences in firefighting skills between novices and experts. Although approaches with augmented reality (AR) or virtual reality (VR) could be considered as methods for analyzing firefighting skills, firefighting activities with AR or VR are less realistic than using teleoperated robots such as unmanned aerial vehicles (UAV) and unmanned ground vehicles (UGV). Therefore, in this paper, we analyze the firefighting skills of experts by comparing the behavior of novices and experts in a firefighting activity using a firefighting teleoperated robot deployed at several fire departments. Human skills develop through five stages of skill levels: novice, advanced beginner, competent, proficient, and expert [25]. In this paper, "novices" corresponds to the "competent" skill level and "experts" corresponds to the "expert" skill level. As a first step toward improving the HMI of teleoperated robots for firefighting, we select a reconnaissance activity as the analysis target; this is because reconnaissance at the site of a fire is one of the most important firefighting activities. We create evaluation items to measure reconnaissance activity according to the basic tactics of firefighting and compare the behavior of novices and experts based on these evaluation items. This analysis result is useful for improving the HMI of firefighting teleoperated robots for reconnaissance, such as those used in [19-21]. Since the experiment in this paper uses the firefighting robot, the results show the difference between novice and experts firefighting skills using the robot. Therefore, we think that researchers of disaster response robots can smoothly use the results of this paper in the design of HMI.

The remainder of this paper is structured as follows: "Evaluation checklist items for reconnaissance" details the evaluation checklist items to be compared between novices and experts for reconnaissance. "Experiment" section describes the experimental setup. "Result" section outlines the results, and "Discussion" section discusses the results in detail. Finally, "Conclusion" section provides the conclusions.

\section{Evaluation checklist items for reconnaissance}

Firefighting activities allow organized firefighting units to regain control of disaster sites and return them to a safe condition using firefighting skills and technologies. Reconnaissance is a firefighting activity; its purpose is to understand the disaster situation (structure damage, the spread of fire, injured persons, and the operating conditions of firefighting equipment) and develop a fire extinguishing and rescue method. In this paper, we define the reconnaissance activity as the reconnaissance required to find a water discharge point, and we confirm whether there is a difference in the approach between novices and experts in this activity. Therefore, we create two sets of evaluation items based on the fundamental tactics of firefighting: one evaluating the reconnaissance activity and the other determining the water discharge point.

\section{Basic firefighting tactics}

All firefighting activities, including reconnaissance, are based on common basic tactics. Basic firefighting tactics for general buildings (for example, wooden and fireprotected buildings) follow the ten principles provided Table 1 [26]. All firefighters learn and practice these tactics at the fire academy over half a year; therefore, even novice firefighters have knowledge of the basic principles of firefighting.

\section{Evaluation items}

We created evaluation items for the reconnaissance activity and for determining the water discharge point using the basic tactics of firefighting. The evaluation items for the reconnaissance activity are listed in Table 1 . In this study, reconnaissance is considered to start after people are evacuated from the area, and therefore, searching for injured persons is not included in Table 2. Next, the evaluation items for selecting a water discharge point are listed in Table 3. We used the Wilcoxon rank sum test to test Tables 2 and 3. This is because we thought that 
Table 1 Ten principles for basic firefighting tactics

\begin{tabular}{|c|c|}
\hline No. & Description \\
\hline 1 & Prioritize search and rescue activities for protecting lives \\
\hline 2 & Perform firefighting activities that prevent the spread of fire to surrounding buildings \\
\hline 3 & $\begin{array}{l}\text { The first team locates a water discharge point near the fire for utilization and stops its firefighting vehicles so that } \\
\text { they will not be an obstacle to teams arriving later }\end{array}$ \\
\hline 4 & For enlarged fires, point a hose at the back or side of the burning building and enter the building from the top floors \\
\hline 5 & In early small-scale fires, point a hose at the front of the burning building to extinguish the fire in one push \\
\hline 6 & The fire spread prevention points are the inner walls, attic spaces, corridors, and stairway entrances \\
\hline 7 & For enlarged fires in a city, point a hose in the leeward direction to mitigate the risk of the fire spreading \\
\hline 8 & $\begin{array}{l}\text { Regardless of the presence or absence of recognition of fire smoke, firefighters and firefighting vehicles should } \\
\text { locate the water discharge point near the fire }\end{array}$ \\
\hline 9 & If a fireproof building faces a burning building, point the hose at the fireproof building \\
\hline 10 & Use ladders and crashing tools proactively \\
\hline
\end{tabular}

Table 2 Evaluation items for reconnaissance activity

\begin{tabular}{ll}
\hline Item name & Description \\
\hline Location of fire & Whether participants consider the location of the fire \\
Influence of fire on the environment & Whether participants consider the spread of fire to surrounding buildings \\
Building entrance & Whether participants check the building entrance to inrush \\
Rapid combustion & Whether participants consider flashover and backdraft \\
Influence of elapsed time & Whether participants consider the progress of fire over time \\
Water utilization & Whether participants check the locations of the water utilization \\
\hline
\end{tabular}

Table 3 Evaluation items for deciding on the water discharge point

\begin{tabular}{|c|c|}
\hline Item name & Description \\
\hline Wind direction & Whether participants check the wind direction \\
\hline Source of fire & Whether participants check the source of the fire \\
\hline Condition of fire & Whether participants check the condition of the fire \\
\hline Environmental conditions & $\begin{array}{l}\text { Whether participants check environmental conditions when } \\
\text { placing the fire engine and hose }\end{array}$ \\
\hline Type of water utilization & Whether participants consider the type of water utilization \\
\hline Type of firefighting vehicle & Whether participants consider the type of firefighting vehicles \\
\hline
\end{tabular}

the result of evaluation items did not follow a normal distribution.

\section{Experiment}

\section{Experiment location}

Figure 1 shows a diagram and photograph of the experimental field, which measured $24 \mathrm{~m}$ (breadth) $\times 36 \mathrm{~m}$ (length). Two fire areas-one simulating a residential area and the other a commercial facility area-were prepared in this field. The residential area, representing crowed houses and condominiums, comprised one building and three passenger cars (red vehicles in Fig. 1b) in the experimental field. The commercial facility was meant to simulate a large shopping mall (a fireproof building) surrounded by a parking lot. The experimental field was prepared by reusing a firefighter training facility.

Each area was divided by road cones and poles to prevent easy movement between the two areas. The reconnaissance starting point, from which the robot moves, is the midpoint of these two areas. Nine marker cones (Fig. 2) represented fire hydrants (yellow) and fire cisterns (red) in the field. Fire points were indicated by flags called "genjibata" (Fig. 3). We used three types of flags in this experiment: white, yellow and red, which respectively indicate the early, growth, and 

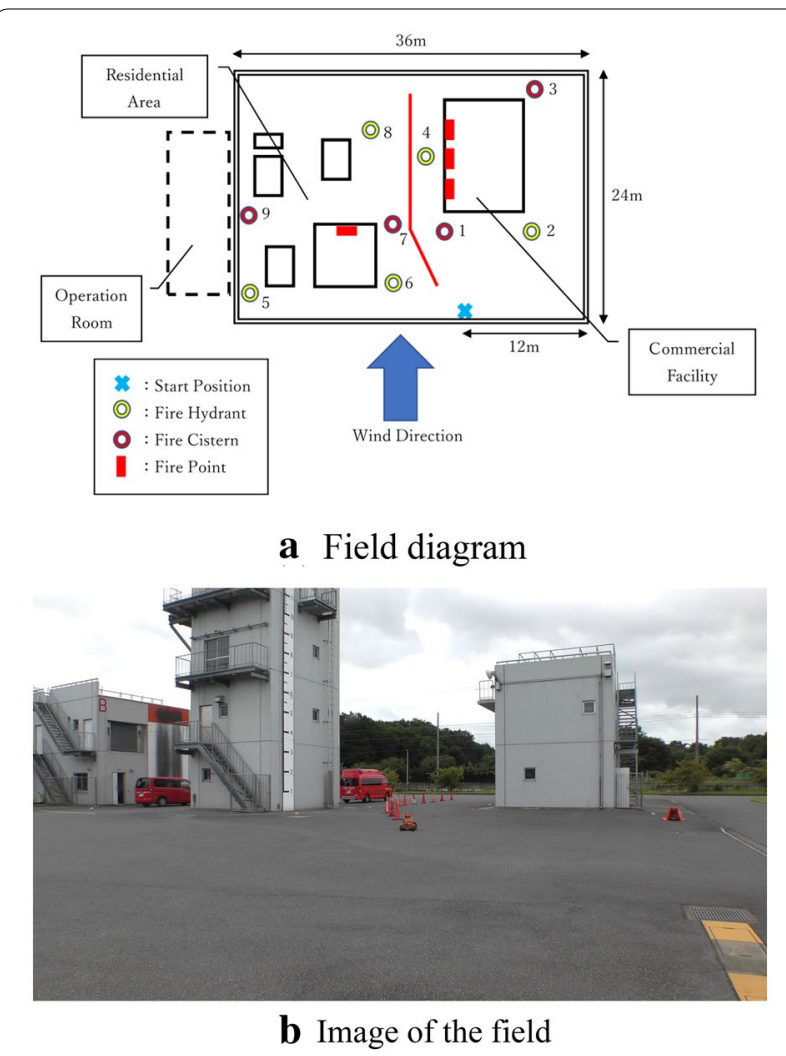

Fig. 1 Experimental field

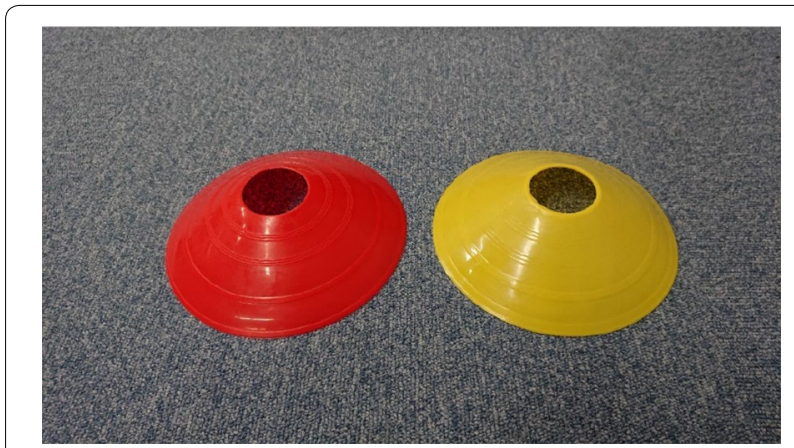

Fig. 2 Water supply markers
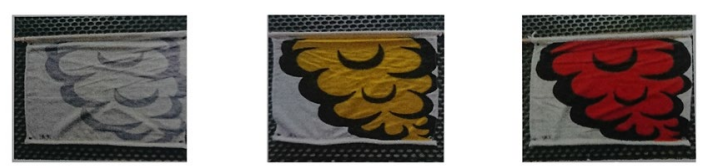

a White smoke flag

b Yellow smoke flag

c Red smoke flag Fig. 3 Fire point flags (genjibata) high-temperature phases of fire smoke. In this experiment, we did not simulate the progression of fire over time.

Because the building and the flag in this experiment were used in actual firefighter trainings, and because the firefighting robot in this experiment has already been equipped in several firefighting headquarters, we thought that this experimental environment would be familiar to firefighters, would be less likely to cause misidentification of the this environment than a computer simulation, and would reduce the variation in the level of understanding of this experiment. Therefore, we did not use a computer simulation but a real robot and environment in this experiment. From the perspective of safety and feasibility, we simulated fire hydrants and fire cisterns with marker cones in consultation with firefighters.

\section{Experimental configuration}

To develop a practical situation, we assumed the following conditions that were decided upon consultation with experienced firefighters. Indeed, these firefighters were not part of the experimental participant group.

Fire situation: An epicentral earthquake has caused fires to break out simultaneously in many places in the prefecture. Participants are firefighters in the A City Fire Department (CFD:A). When all firefighting vehicles in the CFD:A go out for firefighting activities in A City, a request for support is sent from the $B$ City Fire Department (CFD:B) to the CFD:A. The CFD:B has received information about the locations of the fires in B City, but has not yet received water utilization information about B City. All firefighting vehicles in B City are going out for firefighting activities in B City and A City.

- Purpose of reconnaissance: To begin water discharge as soon as the fire engine arrives at this area, the firefighters in the CFD:A reconnoiter with the teleoperated robot and decide on positions for water discharge.

- Reconnaissance timing: For the sake of simplicity, participants start reconnaissance after the evacuation of citizens was completed.

- Teleoperated robot: Fig. 4 shows the reconnaissance robot for firefighting, "FRIGO-M" [27], which was developed by the Mitsubishi Electric TOKKI System Corporation.

This robot is a nonignitable and explosion-proof and has a crawler mechanism and two cameras (one for moving and the other for reconnaissance). Table 4 lists FRIGO-M's basic specifications.

Because operating this robot with an optical cable is difficult, we set it up wirelessly in this experiment. 


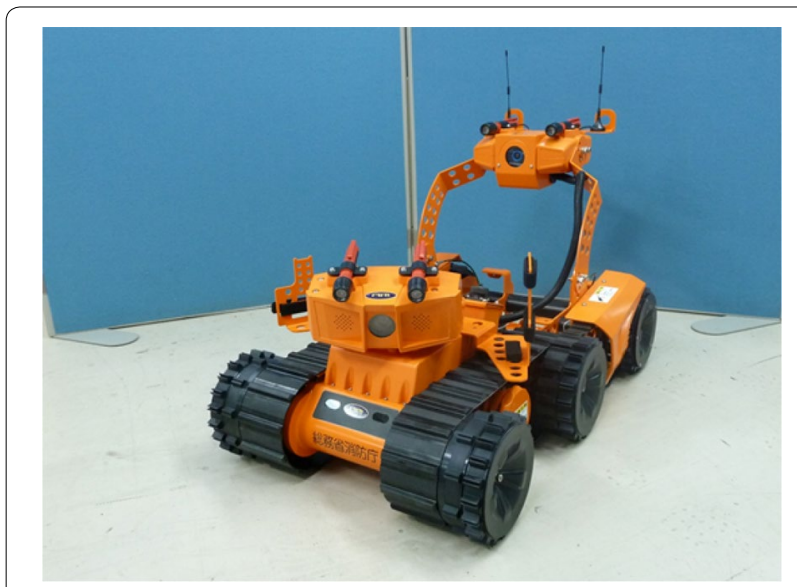

Fig. 4 "FRIGO-M," the firefighting reconnaissance robot

Table 4 Basic specifications of FRIGO-M

\begin{tabular}{|c|c|}
\hline Size & $734 \mathrm{~mm}(\mathrm{~L}) \times 456 \mathrm{~mm}(\mathrm{~W}) \times 654 \mathrm{~mm}(\mathrm{H})$ \\
\hline Mass & $\sim 23 \mathrm{~kg}$ \\
\hline Maximum speed & $\sim 3 \mathrm{~km} / \mathrm{h}$ \\
\hline Disruptability & $\begin{array}{l}\text { FRIGO-M can move on } 200-\mathrm{mm} \text { steps } \\
\text { and at inclinations of } 40^{\circ}\end{array}$ \\
\hline Ingress Protection & IP67 (Sensor section: IP54) \\
\hline $\begin{array}{l}\text { Connection mode (communi- } \\
\text { cation distance) }\end{array}$ & Wireless (80 m) or optical cable (300 m) \\
\hline Uptime with battery & About $2 \mathrm{~h}$ (Ni-MH battery) \\
\hline
\end{tabular}

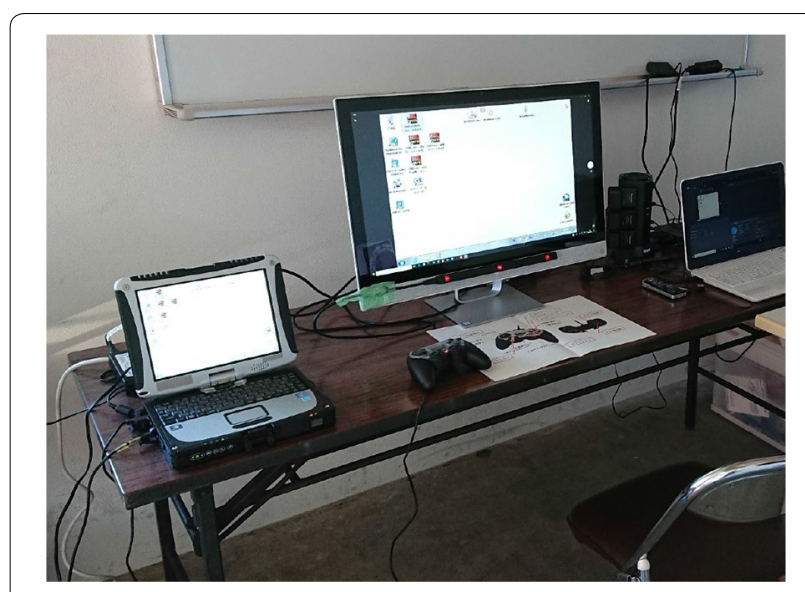

Fig. 5 Operator station for this experiment

Figure 5 shows the work station of the operator: the laptop is used to operate FRIGO-M and the PC monitor is used to measure the eye trajectories of participants. Participants operated this robot using a PC game controller installed on the laptop.

\section{Table 5 Weather condition}

\begin{tabular}{ll}
\hline Temperature (Celsius) & $34^{\circ} \mathrm{C}$ \\
Relative humidity (RH) & $50 \%$ \\
Wind direction & Northwest \\
Wind speed & $10 \mathrm{~m} / \mathrm{s}$ \\
\hline
\end{tabular}

- Experimental participants: Ten firefighters (five novices and five experts) participated in this experiment. It is difficult for young firefighters to acquire firefighting skills because many depend on practical experience; therefore, many years of firefighting are required to become an expert. In this experiment, we define the threshold for an expert as 10 years of firefighting experiences, because most firefighters become sergeants, who focus on protection and rescue, after 10 years of service.

Since our aim was not to compare the skill of the firefighter in operating FRIGO-M, all participants were provided 2 weeks of practice in FRIGO-M's operation before the experiment.

- Force of the fires: Participants were informed that the force of fire in the commercial facility was larger than that in the residential area as preliminary information.

- Firefighting vehicle: Two firefighting vehicles were scheduled to arrive at the fire site after reconnaissance: fire engine A (discharge amount: $1500 \mathrm{~L} / \mathrm{min}$ ) and fire engine B (discharge amount: $2000 \mathrm{~L} / \mathrm{min}$ ). In this experiment, we assume that only one firefighting vehicle can be located in each area.

- Weather conditions: Table 5 summarizes the weather condition considered in this experiment. We assume that the weather condition is that of a day in summer. This is similar to the seasons when this experiment is carried out.

- Data acquisition: To compare the reconnaissance behaviors of novices and experts, we obtained several types of data in this experiment, which are listed in Table 6.

\section{Experimental procedures}

The experiment procedures are detailed below.

(1) Explain the reconnaissance area and purpose to the firefighter, after providing them with a recording sheet (Fig. 6), which is typical of a Japanese recording sheet. 
Table 6 Data acquired

\begin{tabular}{|c|c|c|}
\hline Item name & Data type & Purpose \\
\hline Camera on the teleoperated robot & Movie & To get the eye trajectory of the operator \\
\hline Video camera & Movie & $\begin{array}{l}\text { To get information about the robot's movement trajec- } \\
\text { tory and the operating scene }\end{array}$ \\
\hline Controller data & $\log$ & To get the commands given to the teleoperated robot \\
\hline $\begin{array}{l}\text { Inner sensor data from the teleoperated robot (for exam- } \\
\text { ple, encoder) }\end{array}$ & $\log$ & To get internal information about the teleoperated robot \\
\hline
\end{tabular}

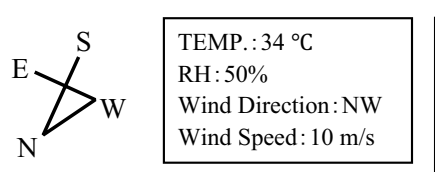

- Please describe the water discharge position for each area as $\mathrm{X}$, the used water utilization as $\circ$, the positions of two fire engines (Fire Engine A : $1500 \mathrm{~L} / \mathrm{min}$; Fire Engine B : $2000 \mathrm{~L} / \mathrm{min}$ ) as $\square$, and the state of laying the hose as a straight line or a curve.

Fig. 6 Recording sheet

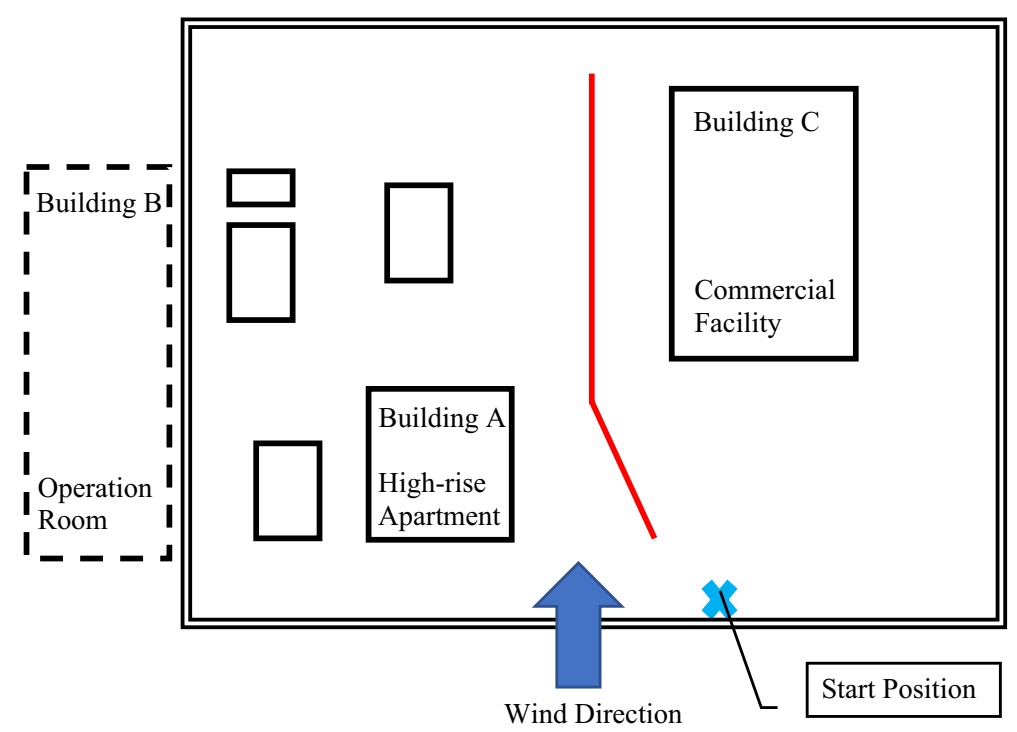

(2) The firefighter operates the teleoperated robot, beginning from the midpoint between the residential area and commercial facility area, for reconnaissance.

(3) After reconnoitering the fire site, the firefighter describes two discharge points on the recording sheet.

(4) The firefighter completes a questionnaire and interview regarding the reconnaissance checklist items.

In order to conduct interviews based on the questionnaire results, the questionnaire is composed of open questions.

- How did you decide which of the commercial facility and residential areas to reconnoiter first?
- How did you select the water utilization points at each area?

- How did you decide on the location of the fire engine at each area?

- What did you pay attention to during reconnaissance?

- What additional functions do you want for this reconnaissance robot? Please provide reasons for each.

\section{Result}

Table 7 shows the responses from the recording sheets of the participants. Figure 7 shows the operating monitor during reconnaissance. Participants can check the direction of movement of the robot, the pan or tilt angle 
Table 7 Results from participants' recording sheets

\begin{tabular}{|c|c|c|c|c|c|}
\hline \multirow[t]{2}{*}{ Index (Career) } & \multirow[t]{2}{*}{ First checking area } & \multicolumn{2}{|c|}{ Water utilization no. } & \multicolumn{2}{|l|}{ Firefighting vehicle } \\
\hline & & $\begin{array}{l}\text { Commercial } \\
\text { facility }\end{array}$ & Residential area & Commercial facility & Residential area \\
\hline \multicolumn{6}{|l|}{ Novices } \\
\hline A (Protection) & Commercial facility & 3 & 7 & Fire engine $B$ & Fire engine $A$ \\
\hline B (Protection) & Commercial facility & 2 & 6 & Fire engine $B$ & Fire engine A \\
\hline C (Rescue) & Commercial facility & 1 & 7 & Fire engine $B$ & Fire engine A \\
\hline D (Protection) & Residential area & 1 & 9 & Fire engine B & Fire engine A \\
\hline E (Protection) & Commercial facility & 2 & 9 & Fire engine $B$ & Fire engine $A$ \\
\hline \multicolumn{6}{|l|}{ Experts } \\
\hline F (Rescue/Protection) & Residential area & 1 & 9 & Fire engine $B$ & Fire engine $A$ \\
\hline G (Protection) & Residential area & 1 & 6 & Fire engine $A$ & Fire engine B \\
\hline H (Rescue) & Commercial facility & 1 & 7 & Fire engine $A$ & Fire engine B \\
\hline I (Protection) & Commercial facility & 1 & 7 & Fire engine A & Fire engine B \\
\hline J (Rescue/Protection) & Residential area & 2 & 6 & Fire engine B & Fire engine A \\
\hline
\end{tabular}

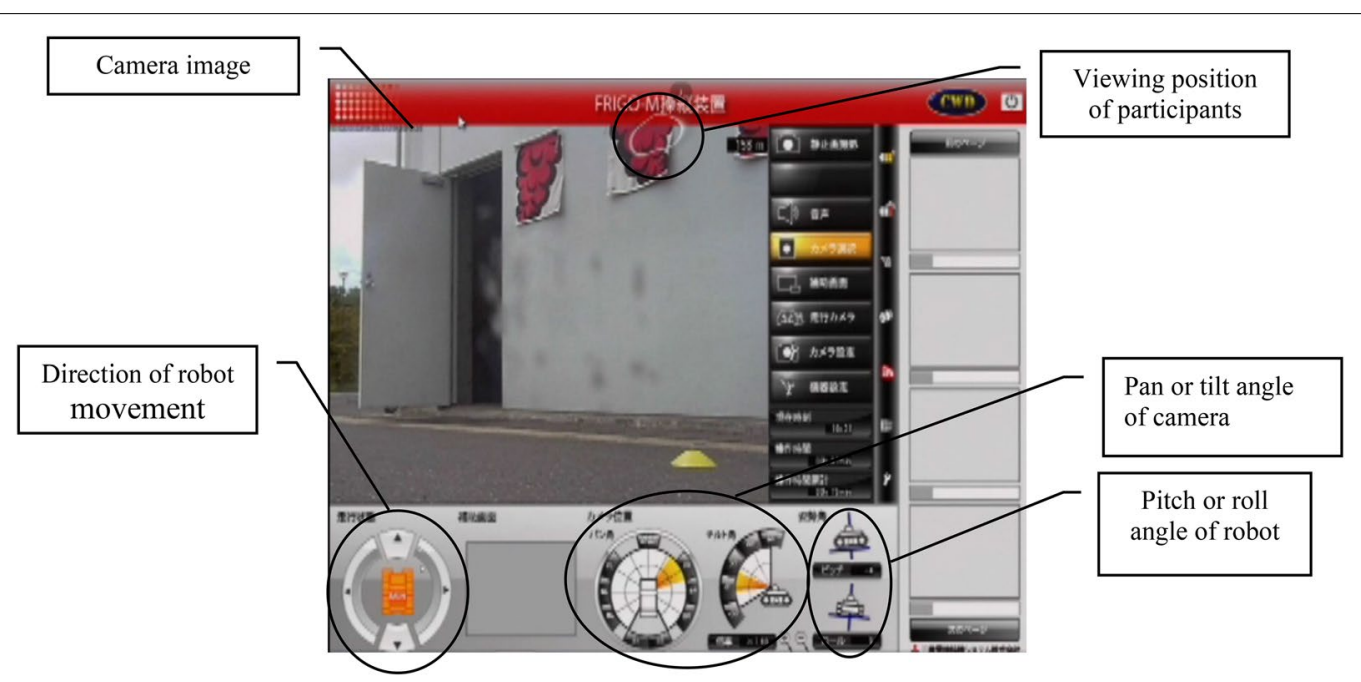

Fig. 7 Operating monitor during reconnaissance

of the camera, and pitch or roll angle of the robot on the operating monitor. The participants operate the robot and camera with a PC game controller to check areas of concern.

Figure 8 shows an example movie measured by the eye tracker for one expert. The green circle surrounds the viewing position of the participant in the eye tracker in Fig. 8. Table 8 summarizes the scene description of Fig. 8. The operator is checking one side of the commercial facility thoroughly. Other experts and novices checked this side of the commercial facility with a similar method. We confirmed from interviews that even if the teleoperated robot is used in this experiment, the path followed by the camera to look around the object is the same as the eye movement in normal reconnaissance activities without the teleoperated robot.

Next, we compared the time taken for reconnaissance by novices and experts. Table 9 summarizes the reconnaissance times of novices and experts for thoroughly checking one side of the commercial facility, their average, and unbiased standard deviation. Although the number of samples (ten) is not large, we assume that the reconnaissance time follows a normal distribution because it occurs under the same conditions. Further, for a large number of samples, it would still follow a normal distribution. We used a F-test to confirm the 


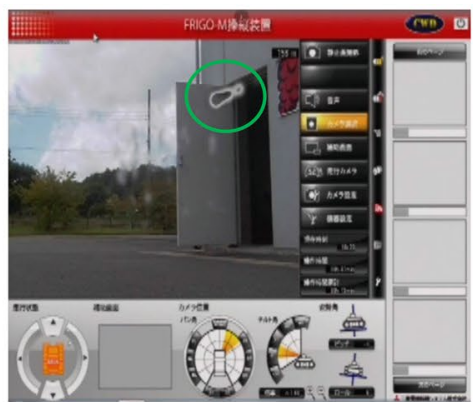

a Scene 1

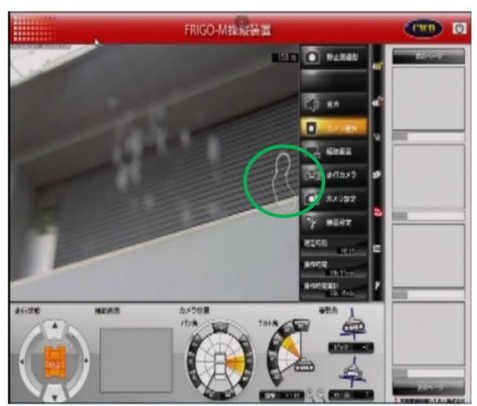

d Scene 4

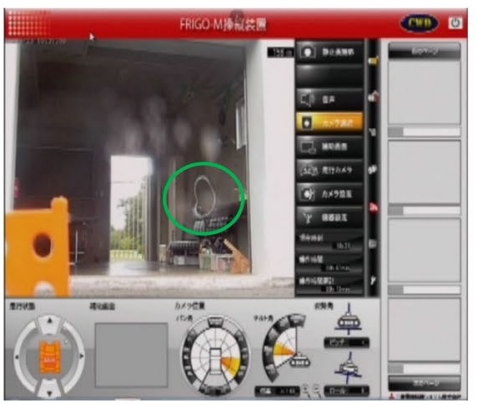

g Scene 7

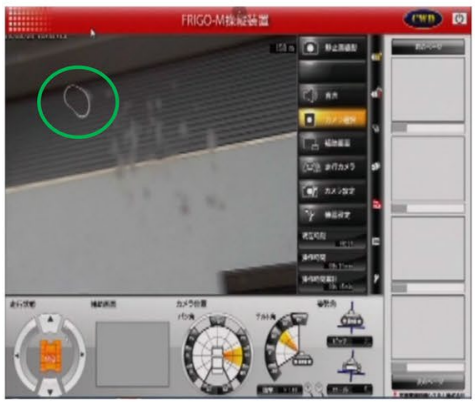

j Scene 10

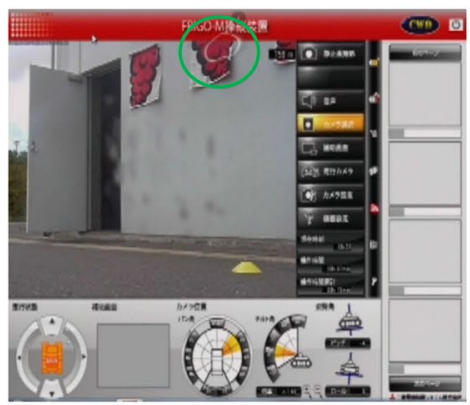

b Scene 2

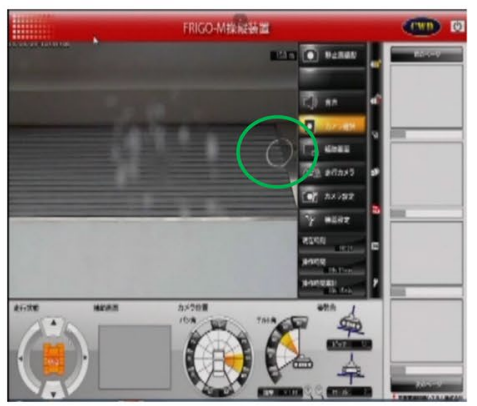

e Scene 5

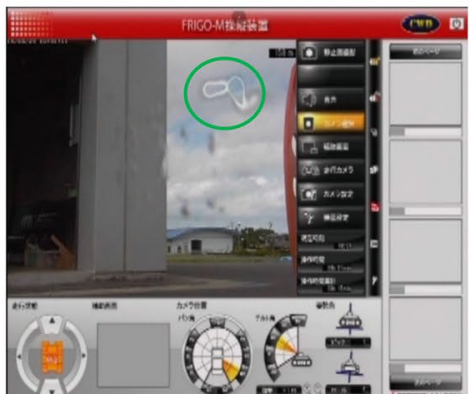

h Scene 8

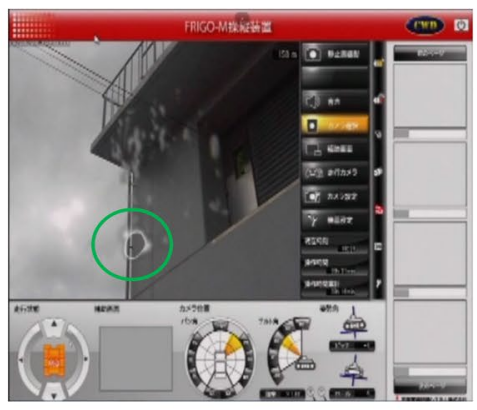

k Scene 11

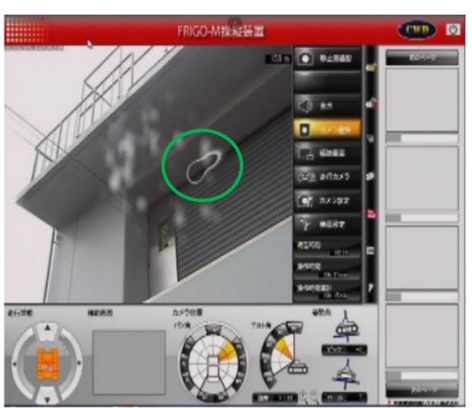

c Scene 3

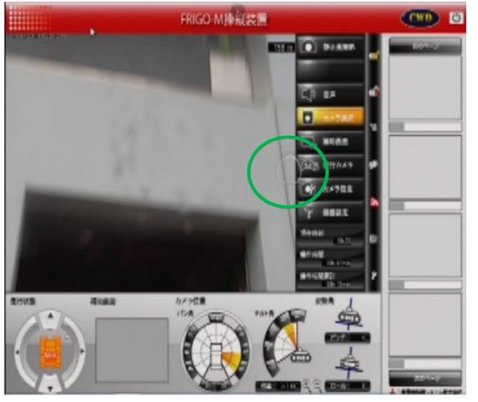

f Scene 6

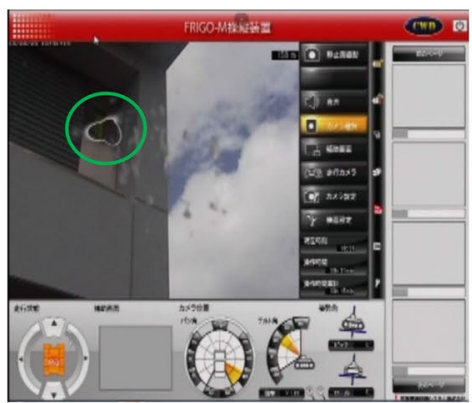

i Scene 9

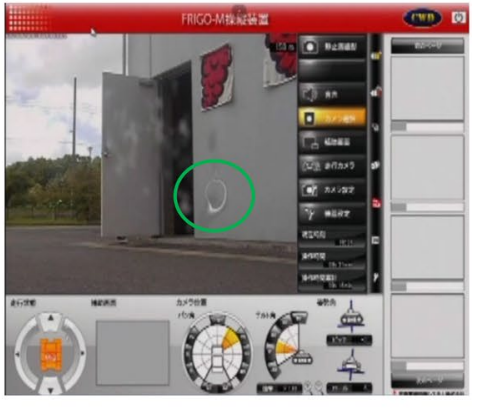

I Scene 12

Fig. 8 Example movie measured via eye tracker for an expert participant 
Table 8 Scene description of Fig. 8

\begin{tabular}{ll}
\hline Scene no. & Description \\
\hline 1 & Check the lower left of the building \\
2 & Check the location of the fire \\
3 & Check the upper left of the building \\
4 & Check the top center of the building \\
5 & Check the upper right of the building \\
6 & Check the right center of the building \\
7 & Check the bottom center of the building \\
8 & Check the lower right of the building \\
9 & Check the upper right of the building again \\
10 & Check the top center of the building again \\
11 & Check the upper left of the building again. \\
12 & Check the lower left of the building again \\
\hline
\end{tabular}

Table 9 Reconnaissance times of novices and experts for thoroughly checking one side of the commercial facility

\begin{tabular}{llll}
\hline Index & $\begin{array}{l}\text { Reconnaissance } \\
\text { time [s] }\end{array}$ & Mean value [s] & $\begin{array}{l}\text { Unbiased } \\
\text { standard } \\
\text { deviation [s] }\end{array}$ \\
\hline Novices & & \\
A & 20 & 21.4 & 5.19 \\
B & 20 & & \\
C & 18 & & \\
D & 30 & & \\
E & 19 & \\
Experts & & \\
F & 20 & \\
G & 18 & \\
H & 24 & \\
I & 20 & \\
J & 30 & \\
\hline
\end{tabular}

presence or absence of a difference between the distributions of novices and experts. The F value obtained from these mean values and unbiased variances is 1.04 . Because the degrees of freedom of both the novice and expert population are $4, \mathrm{~F}_{0.05}$ is 6.39 , based on the $\mathrm{F}$ distribution table (significance level: $p=0.05$ ). Since the $F$ value is smaller than $\mathrm{F}_{0.05}$, there is no significant difference between the two distributions - that is, the distributions have equal variance. Since the populations of novices and experts follow a normal distribution and the distributions of novices and experts have equal variances, we used a t-test to confirm the presence or absence of a significant difference between the means of the population of novices and experts. The $t$ value obtained from this mean value and unbiased variance is 0.06 . Because the degree of freedom for this t-test is $8, \mathrm{t}_{0.05}$ is 2.31 , based on the $\mathrm{t}$ distribution table (significance level: $\mathrm{p}=0.05)$. Since the $\mathrm{t}$ value is smaller than $t_{0.05}$, there was no significant difference between the population means of novices and experts.

We compared the camera operations for reconnaissance by novices and experts. Table 10 summarizes the camera operations of novices and experts for thoroughly checking one side of the commercial facility. In Table 10, the numbers of camera operation show the area that is divided into four sections on one side of the building (Fig. 9). We specified how the camera operation was performed with these sequences of numbers and used levenshtein distance to compare the differences in camera operations between novices and experts. The basis sequence for calculating the levenshtein distances is I, II, III, and IV, the most popular sequence in participants' results.

We used the Wilcoxon rank sum test to confirm the presence or absence of a significant difference between the levenshtein distance of novices and experts listed in Table 10, because we thought that the result of levenshtein distance did not follow a normal distribution. From Table 10, the p value was 0.90, and it was found that there was no significant difference between the two groups.

Therefore, in terms of reconnaissance time and checking order, there is no significant difference between novice and expert populations.

Table 10 Camera operations of novices and experts for thoroughly checking one side of commercial facility

\begin{tabular}{|c|c|c|c|c|c|}
\hline \multirow[t]{2}{*}{ Index } & \multicolumn{4}{|c|}{ Camera operation } & \multirow{2}{*}{$\begin{array}{l}\text { Levenshtein } \\
\text { distance }\end{array}$} \\
\hline & $1 \mathrm{st}$ & 2nd & $3 r d$ & 4th & \\
\hline \multicolumn{6}{|l|}{ Basis } \\
\hline- & l & $\|$ & III & IV & - \\
\hline \multicolumn{6}{|c|}{ Novices } \\
\hline A & IV & III & I & $\|$ & 4 \\
\hline$B$ & IV & III & $\|$ & I & 4 \\
\hline C & l & $\|$ & $\|$ & IV & 0 \\
\hline$D$ & l & $\|$ & $\|$ & IV & 0 \\
\hline$E$ & IV & III & I & $\|$ & 4 \\
\hline \multicolumn{6}{|l|}{ Experts } \\
\hline$F$ & 1 & $\|$ & III & IV & 0 \\
\hline G & IV & III & $\|$ & I & 4 \\
\hline $\mathrm{H}$ & I & $\|$ & III & IV & 0 \\
\hline I & III & IV & 1 & $\|$ & 4 \\
\hline$J$ & IV & III & I & $\|$ & 4 \\
\hline
\end{tabular}




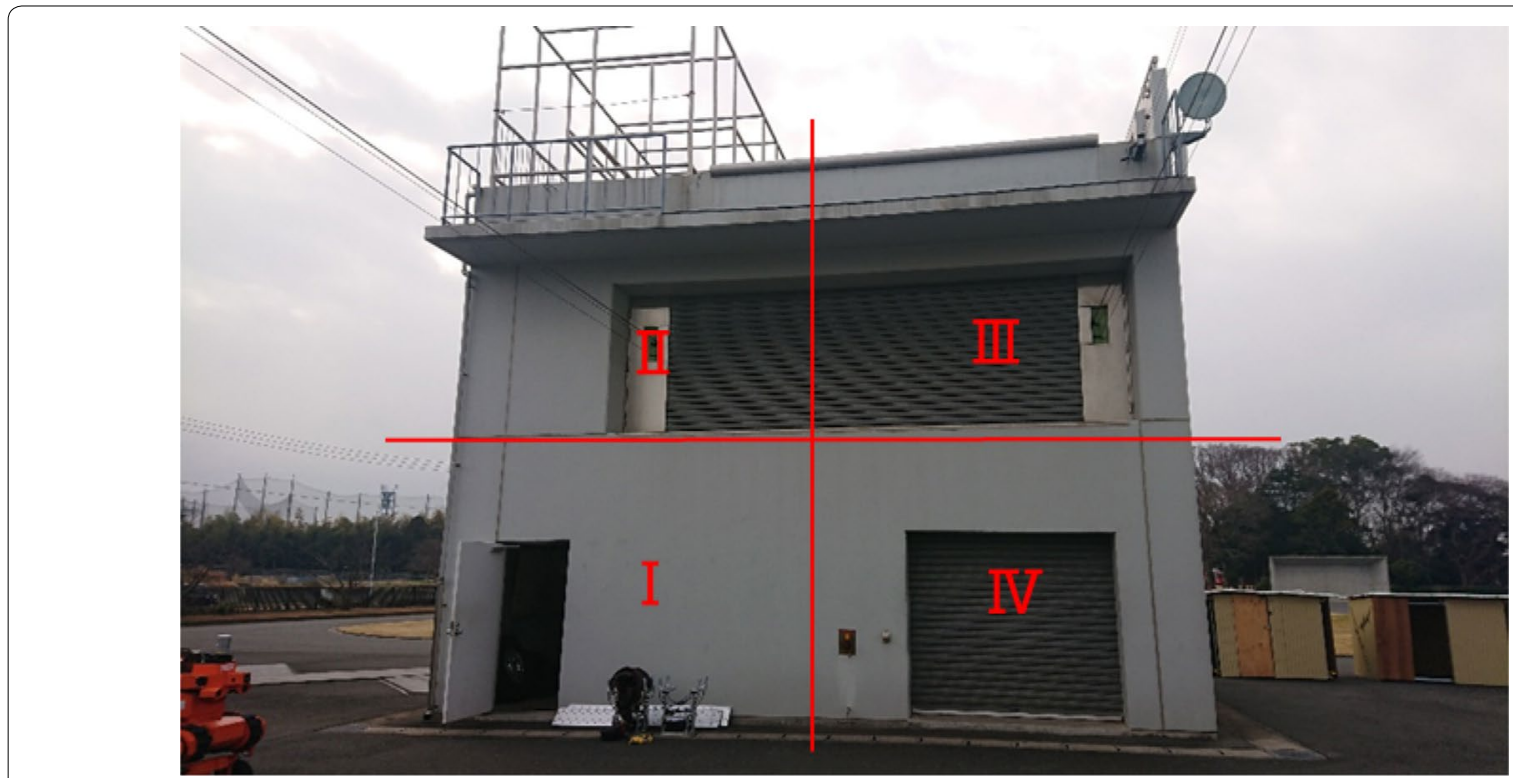

Fig. 9 Area that is divided into four sections on one side of the building

Table 11 Result of the evaluation items for reconnaissance activity

\begin{tabular}{|c|c|c|c|c|c|c|c|c|c|c|}
\hline & \multicolumn{5}{|c|}{ Novices } & \multicolumn{5}{|c|}{ Experts } \\
\hline & A & B & $\mathrm{C}$ & D & $\mathrm{E}$ & $\mathrm{F}$ & G & $\mathrm{H}$ & 1 & $J$ \\
\hline Location of fire & 0 & $\mathrm{O}$ & $\mathrm{O}$ & $\mathrm{O}$ & 0 & O & O & O & 0 & O \\
\hline Influence of fire on the environment & $\times$ & $\times$ & $\times$ & $\mathrm{O}$ & $x$ & O & O & O & 0 & O \\
\hline Building entrance & $x$ & $x$ & $x$ & O & $x$ & O & O & O & O & $\mathrm{O}$ \\
\hline Rapid combustion & $\times$ & $\times$ & $x$ & $\times$ & $\times$ & $x$ & ○ & O & $\bigcirc$ & $\times$ \\
\hline Influence of passed time & $x$ & $x$ & $\times$ & $x$ & $x$ & $x$ & O & O & $x$ & 0 \\
\hline Water utilization & $\bigcirc$ & $\bigcirc$ & $\bigcirc$ & $\bigcirc$ & 0 & O & O & O & $\bigcirc$ & O \\
\hline Total score & 2 & 2 & 2 & 4 & 2 & 4 & 6 & 6 & 5 & 5 \\
\hline
\end{tabular}

Table 12 Result of the evaluation items for deciding on the water discharge point

\begin{tabular}{|c|c|c|c|c|c|c|c|c|c|c|}
\hline & \multicolumn{5}{|c|}{ Novices } & \multicolumn{5}{|c|}{ Experts } \\
\hline & $A$ & B & $\mathrm{C}$ & $\mathrm{D}$ & $E$ & $\mathrm{~F}$ & G & $\mathrm{H}$ & 1 & $J$ \\
\hline Wind direction & $x$ & O & O & 0 & O & $\bigcirc$ & 0 & 0 & O & O \\
\hline Source of fire & $x$ & $x$ & O & O & $\times$ & 0 & 0 & 0 & 0 & 0 \\
\hline Condition of fire & O & O & 0 & O & O & O & 0 & 0 & 0 & 0 \\
\hline Environmental conditions & 0 & 0 & O & O & $x$ & O & 0 & 0 & 0 & $x$ \\
\hline Type of water utilization & 0 & $\mathrm{O}$ & 0 & O & $x$ & 0 & 0 & 0 & 0 & $\mathrm{O}$ \\
\hline Type of firefighting vehicle & 0 & 0 & O & O & $\mathrm{O}$ & O & 0 & 0 & 0 & $\mathrm{O}$ \\
\hline Total score & 4 & 5 & 6 & 6 & 3 & 6 & 6 & 6 & 6 & 5 \\
\hline
\end{tabular}

Tables 11 and 12 show the results of the evaluation items from Tables 2 and 3, respectively. These tables were drawn by integrating the interview and questionnaire results. The total score in Tables 11 and 12 is the total value with a score of 1 if an evaluation item has been checked and 0 if it has not been checked. We used the Wilcoxon rank sum test to confirm the presence or 
absence of a significant difference between the total scores of novices and experts listed in Tables 11 and 12.

From Table 11, the $\mathrm{p}$ value was 0.012 (effect size: $r=0.76$ ); it was found that there was a significant difference between the groups of novices and experts. Because the effect size is higher than 0.50 , a substantial difference was confirmed [28].

From Table 12, the $\mathrm{p}$ value was 0.19 (effect size: $r=0.40$ ), and it was found that there was no significant difference between the two groups.

According to these results, experts evaluate reconnaissance areas with a more multifaceted perspective than novices, even when reconnoitering the same area.

Figures 10 and 11 show the graphs of the evaluation items from Tables 11 and 12, respectively. In these figures, the axis value of each item shows the number of participants who fit each item.

Table 13 show the result of the novices' interviews on the evaluation items. From Table 13, all novices can check more evaluation items if others point out.

\section{Discussion}

This study aimed to investigate the differences between novices and experts for both a reconnaissance activity and for deciding on a water discharge point. We assumed that there would be significant differences for both tasks; however, no significant difference was observed in the task of deciding the water discharge point. We believe that the various shapes and types of building are reasons why there is a significant difference

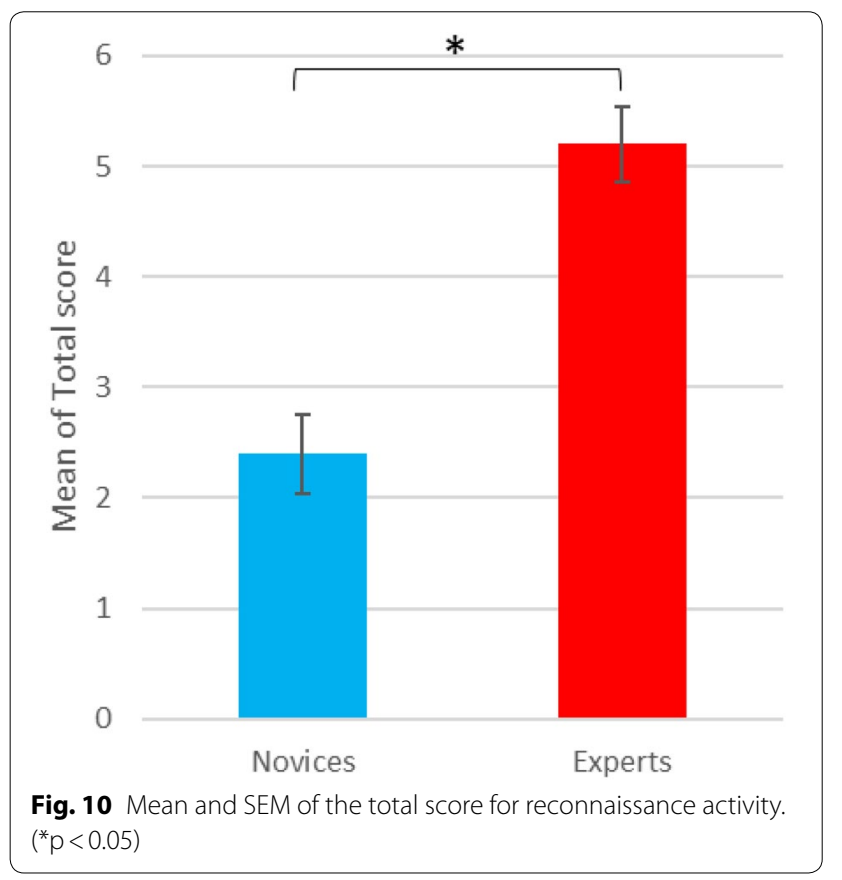

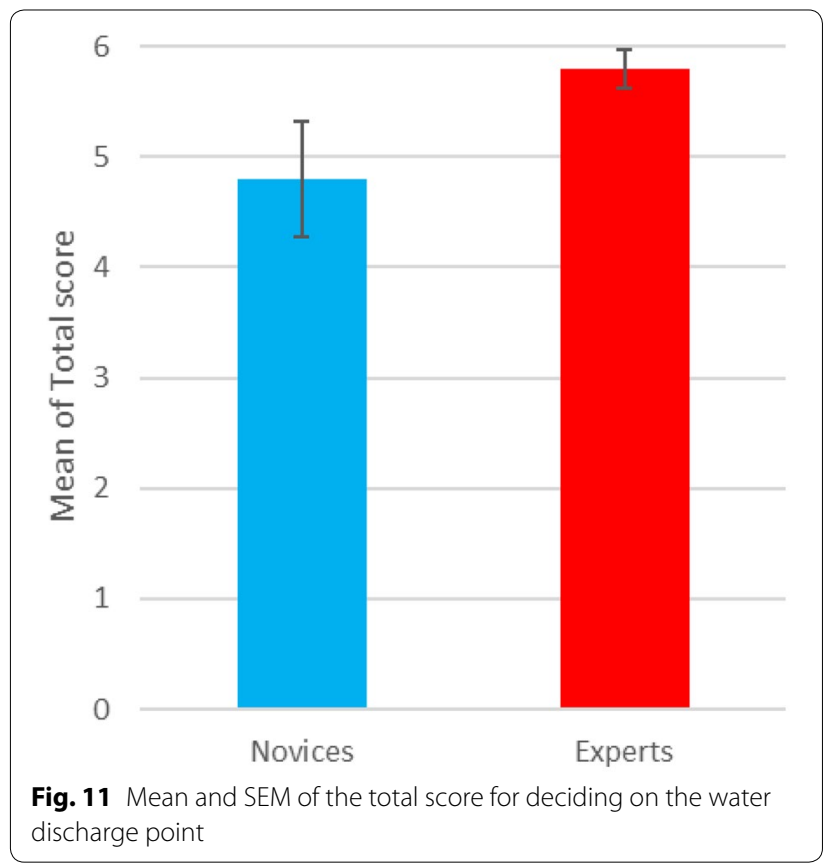

between novices and experts in the evaluation items for the reconnaissance activity. Novices have insufficient and biased experiences against the fire types on buildings, and therefore, it is difficult for them to organize what to check for in a reconnaissance activity. However, experts organize the items to check for reconnaissance activity from their various firefighting experiences.

There was no significant difference in the tends of novices and experts to operate monitor system. We believe that this indicates that both novices and experts are aware of the importance of looking the entirety of the objects without omission to gather information. However, unlike experts, many novices only look at the current situation. It is thought that this is because novices have little firefighting experience and their imagination does not work well for what happens next.

The interviews confirmed that if novices are directed to checklist items by others, they can perform reconnaissance in as multifaceted a manner as experts (Table 13). This may present a method of filling in the gap between the firefighting skill and reconnaissance

\begin{tabular}{|c|c|c|c|c|c|}
\hline & \multicolumn{5}{|c|}{ Index } \\
\hline & $A$ & B & $C$ & D & $E$ \\
\hline $\begin{array}{l}\text { Can check more evaluation items if oth- } \\
\text { ers point out }\end{array}$ & 0 & 0 & 0 & 0 & 0 \\
\hline
\end{tabular}


abilities of novices and experts, such as in determining the water discharge point.

For determining the water discharge point, theories of water discharge (e.g., to discharge water from the windward direction) are common for firefighters independent of the fire types, and we think that there is no significant difference between novices and experts.

From these results, we consider that the evaluation items for deciding on the water discharge point are items that are not affected by differences in experience.

Because the human cognitive resource is limited, the more information the HMI presents, the more ineffective it is; we believe that information suitable for the purpose should be extracted and presented appropriately.

The result of the recording sheets of the participants (Table 7) and individual evaluation items (Figs. 12 and 13) are discussed in the supplementary information. However, these discussion needs to cover the qualitative differences between novices and experts. To confirm the significant difference in the results for individual evaluation items, the sample size used in this study is small, and therefore, a more detailed experiment is necessary for future work.

Table 7 indicates the differences between novices and experts as seen in the reconnaissance order and selection of firefighting vehicle. Novices tended to check commercial facility area first and to select the fire engine $\mathrm{B}$ for this area, whereas experts tended to check the residential area first and selected diverse firefighting vehicles. From the results of interviews and questionnaires, we confirmed that the preliminary information given influenced this decision, as the force of fire in the commercial facility area was greater than in the residential area. Almost all novices were sensitive to this information, they checked the commercial facility area first without considering the spread of fire in the residential area, and they then selected the fire engine $B$ for its discharge amount. Although all firefighters learn the principle of focusing on preventing the spread of fire to surrounding buildings, almost all novices were distracted by the preliminary information. In contrast, all experts acted on this principle without being distracted by the preliminary information and considered more situations than novices. Even though experts $\mathrm{H}$ and I checked the commercial facility area first, this reason was to confirm that there was no danger of the fire spreading outside the commercial facility area, which they were not familiar with. The above results indicate that novices tend to be anchored in preliminary information.

Figure 12 indicates the differences between novices and experts in their reconnaissance of the influence of fire on the environment, the building entrance, rapid

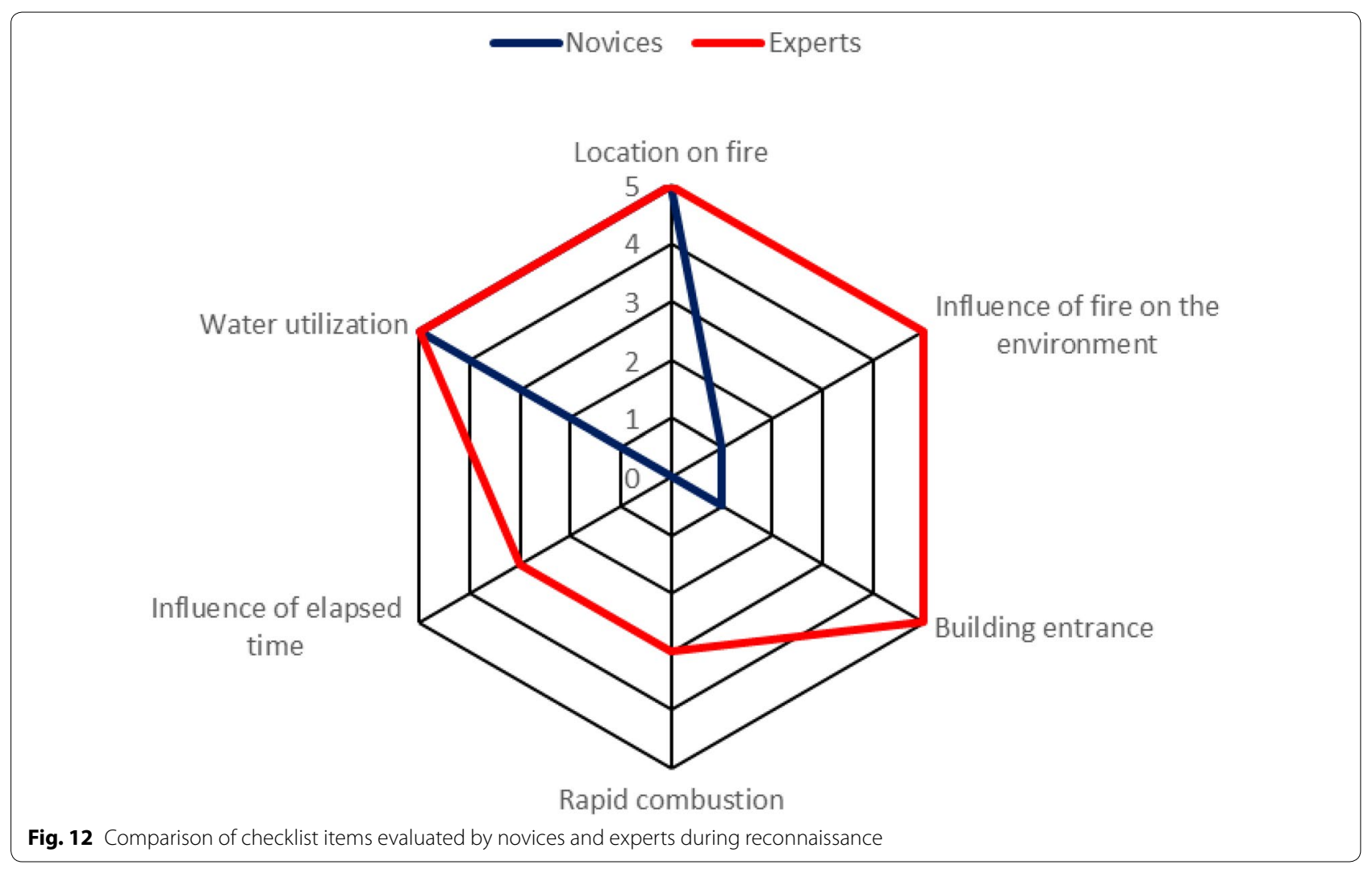




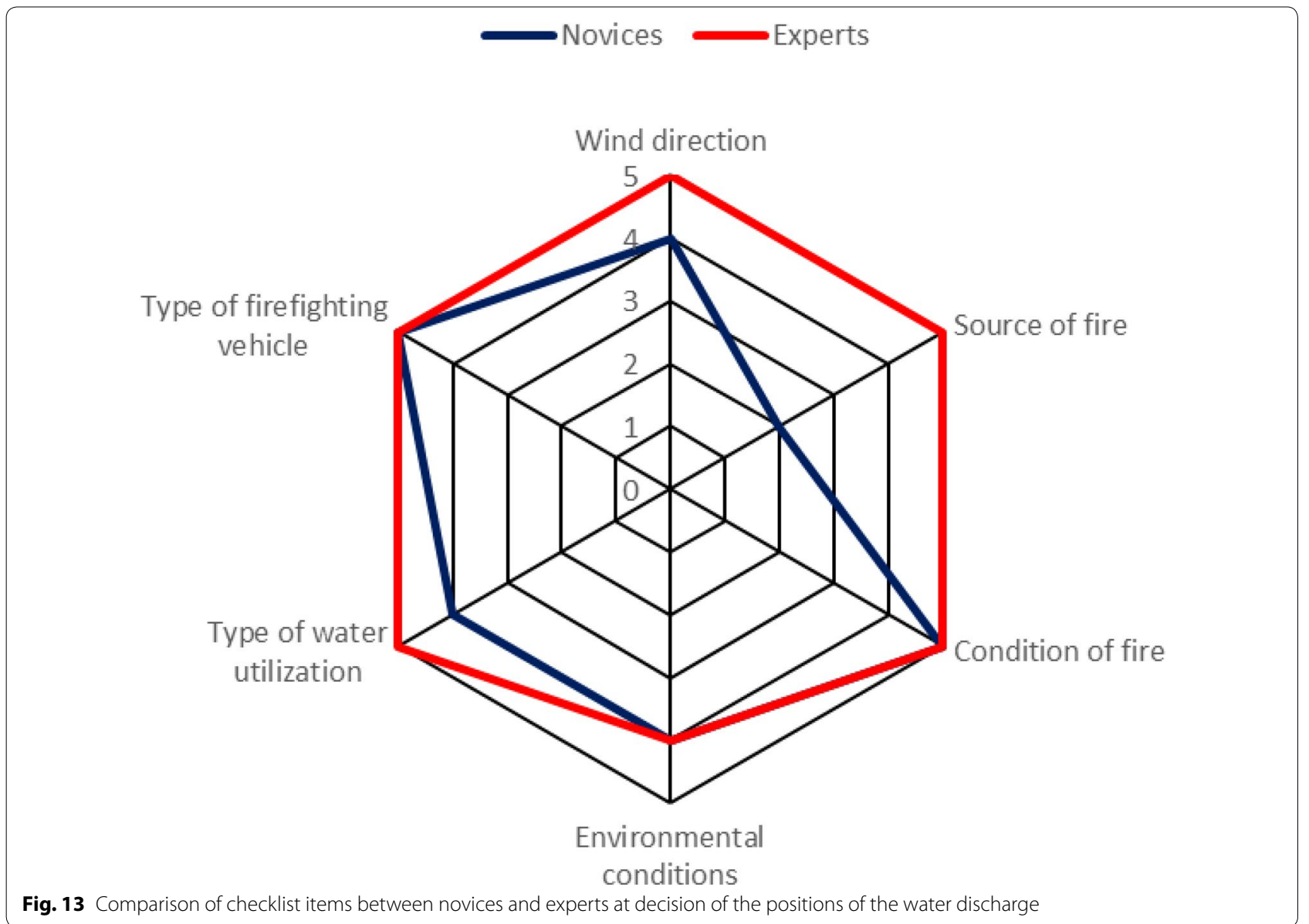

combustion, and the influence of elapsed time. These items are difficult to assess and the assessment depends on many years of firefighting experience.

Figure 13 indicates the difference between novices and experts in checking the source of fire. Fire extinguishing methods change according to the source of fire. Since experts understand that the cause of fire is important for effective firefighting, they tend to check not only the location of the fire but also its source.

\section{Conclusion}

In this study, we analyzed the firefighting skills of experts by comparing the behavior of novices and experts in a firefighting activity with teleoperated robots. By comparing the behaviors of novices and experts during reconnaissance, we confirmed that the difference between novices and experts is the presence or absence of multifaceted evaluation. Experts evaluate the reconnaissance areas in a multifaceted way and act based on that result. In contrast, novices evaluate a limited range of the reconnaissance areas. As stated in "Introduction" section, "novices" corresponds to the "competent" skill level and "experts" corresponds to the "expert" skill level in this paper. The "competent" skill level indicates the ability to identify important items within a limited range. Therefore, many novices cannot evaluate reconnaissance areas in as multifaceted a manner as experts can.

Interviews confirmed that if checklist items are pointed out to novices by others, novices can perform as multifaceted an evaluation as experts. Based on the results of this experiment, we believe that by developing the HMI of firefighting teleoperated robots that presents evaluation items on the operation screen, reconnaissance from a multifaceted perspective similar to that of an experienced firefighter is possible, even for novice operators. Casper et al. [29] reported that more research on perceptual user interfaces was needed for future development of HMI. We believe that such a HMI with the function to present information checked by experts is one of the good perceptual user interfaces. Since the experiment in this paper uses the firefighting robot, the analysis results of this paper extract the firefighting skills using the robot. Therefore, we think that the extracted skill, the multifaceted perspective, can be directly used as necessary elements in the design of HMI for disaster response robots. 
Further, by reflecting the test results of this experiment in the education system for firefighters, we expect novices to develop an early understanding of reconnaissance skills.

\author{
Abbreviations \\ HMI: Human Machine Interface; CFD: City Fire Department; AR: Augmented \\ reality; VR: Virtual reality; UAV: Unmanned aerial vehicles; UGV: Unmanned \\ ground vehicles.
}

\section{Acknowledgements}

This work was partially supported by JSPS KAKENHI Grant Number $20 \mathrm{H} 04261$.

\section{Authors' contributions}

YT conducted all research and experiments. HA and JO conducted a research concept. All authors read and approved the final manuscript.

\section{Competing interests}

The authors declare that they have no competing interests.

\begin{abstract}
Author details
1 Department of Precision Engineering, Graduate School of Engineering, The University of Tokyo, Tokyo 113-8656, Japan. ${ }^{2}$ National Research Institute of Fire and Disaster, Tokyo 182-0082, Japan. ${ }^{3}$ Research into Artifacts, Center for Engineering (RACE), School of Engineering, The University of Tokyo, Tokyo 113-8656, Japan
\end{abstract}

Received: 26 December 2019 Accepted: 15 June 2020 Published online: 20 June 2020

\section{References}

1. Schilling K and Driewer F (2005) Remote control of mobile robots for emergencies. In: Proceedings of the 16th IFAC World Congress, Prague, Czech Republic, pp 65-70

2. Baker M, Casey R, Keyes B, and Yanco HA (2004) Improved interfaces for humanrobot interaction in urban search and rescue. In: 2004 IEEE international conference on systems, man and cybernetics, Hague, Netherlands, pp 2960-2965

3. Bruemmer DJ, Nielsen CW, and Gertman DI (2008) How training and experience affect the benefits of autonomy in a dirty-bomb experiment. In: Proceedings of the 3rd ACM/IEEE international conference on humanrobot interaction, Amsterdam, Netherlands, pp 161-168

4. Olivares R, Zhou C, Bodenheimer B, and Adams JA (2003) Interface evaluation for mobile robot teleoperation. In: Proceedings of the ACM southeast conference, Savannah, GA, USA, pp 112-118

5. Labonté D, Boissy P, Michaud F (2010) Comparative analysis of 3D robot teleoperation interfaces with novice users. IEEE Trans Syst Man Cybern Part B 40(5):1331-1342

6. Gancet J, Motard E, Naghsh A, Roast C, Arancon MM, and Marques L (2010) User interfaces for human robot interactions with a swarm of robots in support to firefighters. In Proceedings of IEEE international conference on robotics and automation, Anchorage, AK, USA, pp 2846-2851

7. Kim J-K, Jo S, Lattimer BY (2016) Feature selection for intelligent firefighting robot classification of fire, smoke, and thermal reflections using thermal infrared images. J Sens. https://doi.org/10.1155/2016/8410731

8. Marjovi A, Marques L, and Penders J (2009) Guardians robot swarm exploration and firefighter assistance. Presented at the IEEE/RSJ international conference on intelligent robots and systems, St. Louis, MO, USA, Oct 10-15

9. Rakib T and Sarkar MAR (2016) Design and fabrication of an autonomous firefighting robot with multisensor fire detection using PID controller. In: Proceedings of the 5 th international conference on informatics, electronics and vision, Dhaka, Bangladesh, pp 909-914

10. Bruemmer DJ, Boring RL, Few DA et al.(2004) I call shotgun!": An evaluation of mixed-initiative control for novice users of a search and rescue robot. In: Proceedings of the 2004 IEEE international conference on systems, man and cybernetics, Hague, Netherlands, pp 2847-2852

11. Yokokohji Y, Tubouchi T, Tanaka A, Yoshida T, Koyanagi E, Matsuno F, Hirose S, Kuwahara H, Takemura F, Ino T, Takita K, Shiroma N, Kamegawa T, Hada
Y, Osuka K, Watasue T, KimuraT, Nakanishi H, Horiguch Y, Tadokoro S, and Ohno K (2006) Guidelines for human interface design of rescue robots. In: Proceedings of SICE-ICSE international joint conference, Busan, Korea, pp 3455-3460

12. Kumar R, Jog A, Vagvolgyi B, Nguyen $H$, Hager $G$, Chen CCD, Yuh D (2012) Objective measures for longitudinal assessment of robotic surgery training. J Thorac Cardiovasc Surg 143:528-534

13. Guru KA, Esfahani ET, Raza SJ, Bhat R, Wang K, Hammond Y, Wilding G, Reabody JO, Chowriappa AJ (2015) Cognitive skills assessment during robot-assisted surgery: separating the wheat from the chaff. BJU Int. 115(1):166-174

14. Morioka M, Sakakibara S (2010) A new cell production assembly system with human-robot cooperation. CIRP Ann 59(1):9-12

15. Roy S, Kieson E, Abramson C, and Crick C (2017) Semantic structure for robotic teaching and learning. Presented at the 26th IEEE international symposium on robots and human interactive communication, Lisbon, Portugal, Aug 28-Spt 1

16. Lewis B, Tastan B and Sukthankar G (2013) An adjustable autonomy paradigm for adapting to expert-novice differences. In: Proceedings of the 2013 IEEE/RSJ international conference on intelligent robots and systems, Tokyo, Japan, pp 1656-1662

17. Ishii N and Miwa K (2002) Interactive processes between mental and external operations in creative activity: A comparison of experts' and novices' performance. In Proceedings of the 4th conference on creativity \& cognition, Loughborough, UK, Oct, pp 178-185

18. Suebnukarn S, Phatthanasathiankul N, Sombatweroje S, Rhienmora P, Haddawy P (2009) Process and outcome measures of expert/novice performance on a haptic virtual reality system. J Dent 37(9):658-665

19. MacDorman KF, Whalen TJ, Ho C-C, Patel H (2011) An improved usability measure based on novice and expert performance. J. Hum-Comput Interact 23(3):280-302

20. Torrey C, Powers A, Marge M, Fussell SR, and Kiesler S (2006), Effects of adaptive robot dialogue on information exchange and social relations. In: Proceedings of the 1st ACM SIGCHI/SIGART international conference on human-robot interaction, Salt Lake City, UT, 2006, pp 126-133

21. Rafii-Tari H, Liu J, Lee S-L, Bicknell C, and Yang G-Z (2013) Learning-based modeling of endovascular navigation for collaborative robotic catheterization. In: Proceeding of the medical image computing and computerassisted intervention, Nagoya, Japan, pp 369-377

22. Huang Z, Lin C, Kanai-Pak M, Maeda J, Kitajima Y, Nakamura M, Kuwahara $\mathrm{N}$, Ota J (2017) Impact of using a robot patient for nursing skill training in patient transfer. IEEE Trans Learn Technol 10(3):355-366

23. Fire and Disaster Management Agency (2010) Shoubou katsudou nado no chishiki denshou ni kansuru chousa kentou houkokusho. [Survey report on knowledge and technology succession of firefighting activities, etc]. Japan, http://www.fdma.go.jp/neuter/topics/houdou/h22/2203/22033013ho udou/00-1_menyu.pdf, Japanese

24. Ohno K, Ogawa Y, Suwa H, Otha T (2013) Development of firefighting knowledge succession support SNS in Tokyo fire department (Tokyo shoubouchou ni okeru shoubou katsudou keiken no denshou o shien suru SNS no teian). IPS J 54(1):284-294 (Japanese)

25. Dreyfus SE (2004) The five-stage model of adult skill acquisition. Bull Sci Technol Soc 24(3):177-181

26. Japan Association for Fire Science and Engineering (2018) Kasai binran 4th edition. [Handbook for fire science and engineering 4th edition]. Japan, pp 1126-1143, Japanese

27. Mitsubishi Electric TOKKI System Corporation (2008) Reconnaissance robot for firefighting "FRIGO-M". Japan, [Online] Available: http://www.melos.co.jp/ products/crawler.html

28. Field A (2017) Discovering statistics using IBM SPSS statistics, 5th edn. Sage, Thousand Oaks

29. Casper J, Murphy RR (2003) Human-robot interactions during the robotassisted urban search and rescue response at the World Trade Center. IEEE Trans Syst Man Cybern Part B 33(3):367-375

\section{Publisher's Note}

Springer Nature remains neutral with regard to jurisdictional claims in published maps and institutional affiliations. 